------Jou. Raf. Sci., Vol. 20, No.4 pp 52- 57, 2009------

\title{
Synthesis of some Acetylenic Amines Derivatives by Mannich Reaction
}

\author{
Haiffaa Y. Hussin \\ Department of Chemistry \\ College of Science \\ Mosul University
}

(Received 4 /5 / 2009 ; Accepted 28 / 6 / 2009)

\begin{abstract}
Some acetylenic amine derivatives containing nitrogen bases (cytosine, uracil) were synthesized through Mannich reaction which involved reaction of N-propargyl cytosine or uracil with paraformaldehyde and secondary amines. The structure of synthesized compounds have been confirmed depending on the physical and spectral data.
\end{abstract}

Key words: Acetylenic amines derivatives, Mannich reaction.

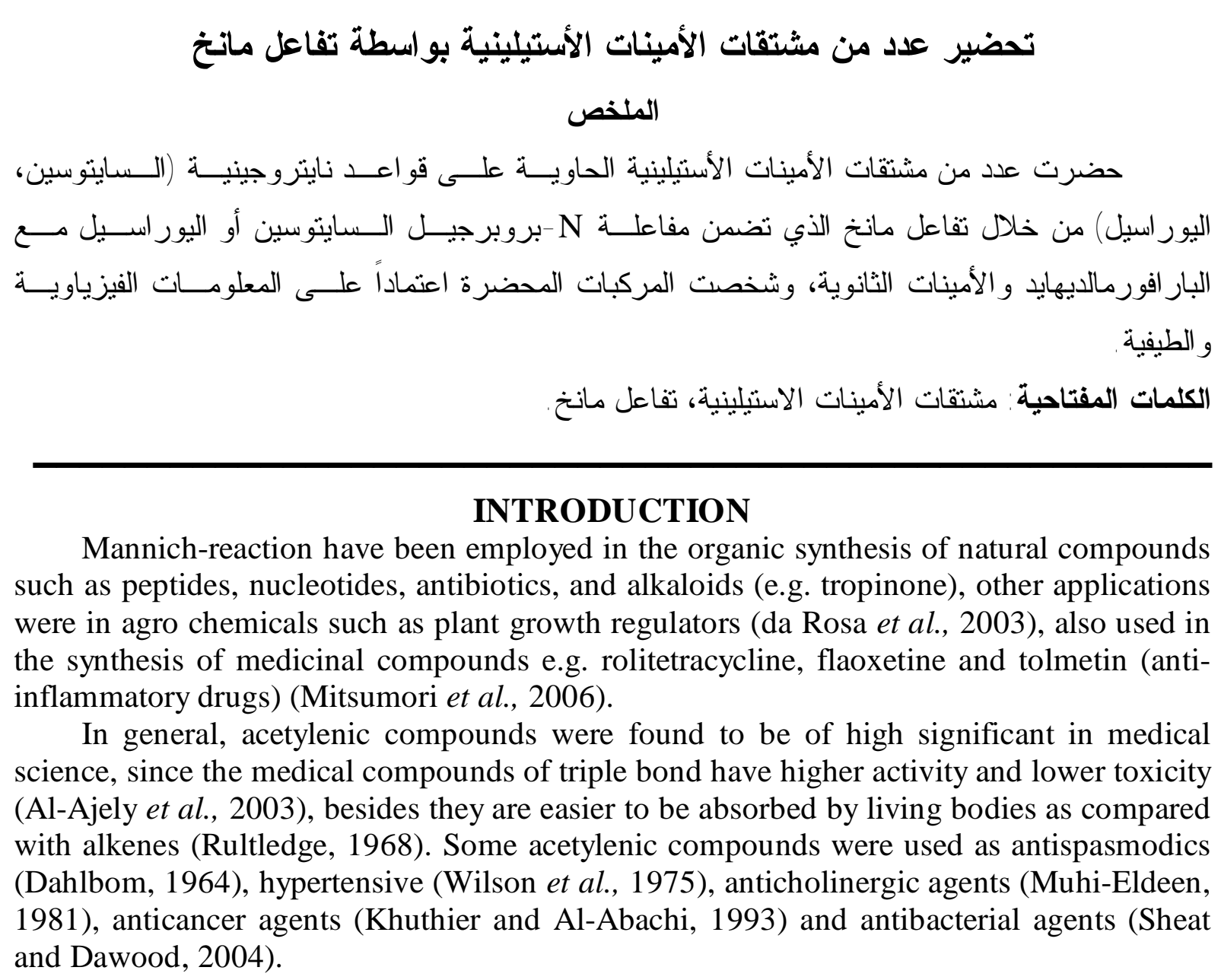


On the other hand, many compounds containing cytosine nucleus were found to possess human anti-tumor activity (Creasy et al., 2006), other compounds containing uracil group were found to be as a new type of anticancer agents (Yamamoto, 1981). Accordingly, we described here an approach to synthesize some aminoacetylenic compounds containing Cytosine(4-amino-2-hydroxypyrimidine) and Uracil (2,4-dihydroxypyrimidine) moieties to improve the expected biological activities of such compounds.

\section{EXPERIMENTAL}

Melting point were determined using electrothermal 9300 melting point apparatus and are uncorrected. IR. spectra were recorded by Pye-Unicam SP1100 Spectrophotometer as $(\mathrm{KBr})$ disc. UV. Spectra were recorded on shimadzu (UV-160) UV-visible spectrophotometer using absolute ethanol as a solvent.

\section{Preparation of N-propargyl cytosine [4-(N-propargylamino)-2-hydroxy pyrimidine] (I) (Redha et al., 2002):}

Propargyl bromide (1.18 gm, 0.01 mole) was added dropwise to a solution of cytosine (1.11 gm, 0.01 mole) in ethanol $(50 \mathrm{ml})$ with stirring. The mixture was refluxed for $5 \mathrm{hrs}$, then it was concentrated by heating and cooled. The white solid product was filtered, washed with ethanol and recrystallized from benzene to afford compound (I) as a white crystals of (89\%) yield and m.p. (294-296 $\left.{ }^{\circ} \mathrm{C}\right)$. Compound (I) showed the following spectral data:
$3169 \mathrm{~cm}^{-1} \quad(\mathrm{br})$
$v \equiv \mathrm{C}-\mathrm{H}, \quad 2120 \mathrm{~cm}^{-1}$
(w) $\quad v^{C} \equiv \mathrm{C}, \quad 1650$
$\mathrm{cm}^{-1}$
(s) $\mathrm{v} \quad \mathbf{C}=\mathbf{O}$,
$1620 \mathrm{~cm}^{-1}(\mathrm{~s}) \cup \mathbf{C}=\mathbf{N} \&$ v $\mathbf{C}=\mathbf{C}, \lambda \max ($ abs. EtOH) $268 \mathrm{~nm}$.

\section{Preparation of N-(4-substitutedaminobut-2-ynyl) cytosine ( Ia-e ): \\ General method (Mannich Reaction) (Afaf et al., 2000):}

A mixture of paraformaldehyde (0.9 gm, 0.001 mole) and appropriate secondary amine $(0.015$ mole $)$ in absolute ethanol $(10 \mathrm{ml})$ was refluxed till clear solution was obtained. Compound (I) ( $0.59 \mathrm{gm}, 0.004$ mole) was heated in absolute ethanol (10 ml), then added to the first reaction mixture and refluxed for ( $2 \mathrm{hrs})$. The mixture was concentrated by heating and the separated product was filtered off and recrystallized form chloroform petroleum ether $\left(80-100{ }^{\circ} \mathrm{C}\right)$ to give the desired compounds (Ia-e). The physical and spectral data of compounds (Ia-e) were listed in Table (1).

\section{Preparation of 3-(N-propargyl) uracil (II) (Sheat and Dawood, 2004):}

A cooled solution of sodium hydroxide $(1.36 \mathrm{gm}, 0.034$ mole $)$ in ethanol $(50 \mathrm{ml})$ was added to a cooled solution of uracil $(3.8 \mathrm{gm}, 0.034 \mathrm{~mole})$ in ethanol $(50 \mathrm{ml})$ with stirring and cooling at $0^{\circ} \mathrm{C}$. Propargyl bromide ( $4 \mathrm{gm}, 0.034 \mathrm{~mole}$ ) was added dropwise with stirring. After the addition is completed, the reaction mixture was refluxed for ( $3 \mathrm{hrs}$ ) with continuous stirring, then extracted with chloroform $(2 \times 50 \mathrm{ml})$. The chloroform extracts were dried with anhydrous magnesium sulphate, then filtered and the solvent was removed in vacuum. The precipitate was recrystallized from benzene-petroleum ether 
$\left(80-100{ }^{\circ} \mathrm{C}\right)$ to afford compound (II) as white crystals of $(75 \%)$ yield and m.p. $\left(132-133{ }^{\circ} \mathrm{C}\right)$. Compound (II) showed the following spectral data:

$3236 \mathrm{~cm}^{-1}$ (s) v $\equiv \mathrm{C}-\mathrm{H}, 2118 \mathrm{~cm}^{-1}$ (w) v C $\equiv \mathrm{C}, 1717 \mathrm{~cm}^{-1}$ (s) v C=O asym, $1689 \mathrm{~cm}^{-1}$ (s) v $\mathbf{C}=\mathbf{O}$ sym (for imidic group), $1622 \mathrm{~cm}^{-1}$ (m) $v \quad \mathbf{C}=\mathbf{C}$, $3418 \mathrm{~cm}^{-1}$ (br) vN-H, $\lambda \max ($ abs. EtOH) $250 \mathrm{~nm}$.

Preparation of N-(4-aminobut-2-ynyl)uracil (IIa-e) (Redha et al, 2002):

The compounds (IIa-e) were prepared by following the above mentioned procedure for compound (Ia-e) and recrystallized from benzene. The physical and spectral data of compounds (Ia-e, IIa-e) were listed in Table (1).

Table 1: physical and spectral data of the synthesized compounds (Ia-e, IIa-e)

\begin{tabular}{|c|c|c|c|c|c|c|c|}
\hline \multirow{2}{*}{$\begin{array}{c}\text { Compd. } \\
\text { NO. }\end{array}$} & \multirow{2}{*}{$\begin{array}{c}\text { Yield } \\
\%\end{array}$} & \multirow{2}{*}{ m.p. ${ }^{\circ} \mathrm{C}$} & \multicolumn{4}{|c|}{ IR. $\left(\mathrm{cm}^{-1}\right)(\mathrm{KBr})$} & \multirow{2}{*}{$\begin{array}{c}\text { UV } \\
(\mathbf{E t O H}) \\
\lambda \max (\mathbf{n m})\end{array}$} \\
\hline & & & $\begin{array}{c}\text { v } \mathrm{C}=\mathbf{O} \\
(\mathrm{s})\end{array}$ & $\begin{array}{c}\mathrm{C}=\mathrm{N} \\
(\mathrm{s})\end{array}$ & $\begin{array}{c}v^{v C}=\mathrm{C} \\
(\mathrm{s})\end{array}$ & $\begin{array}{c}\text { vN-H } \\
\text { (br) }\end{array}$ & \\
\hline Ia & 60 & $242-244$ & 1647 & \multicolumn{2}{|c|}{1636} & 3446 & 280 \\
\hline $\mathrm{Ib}$ & 63 & $158-161$ & 1646 & \multicolumn{2}{|c|}{1614} & 3418 & 260 \\
\hline Ic & 50 & $188-190$ & 1655 & \multicolumn{2}{|c|}{1625} & 3443 & 286 \\
\hline Id & 55 & $239-241$ & 1653 & \multicolumn{2}{|c|}{1626} & 3421 & 282 \\
\hline Ie & 40 & $80-82$ & 1652 & \multicolumn{2}{|c|}{1617} & 3421 & 280 \\
\hline IIa & 53 & $323-325$ & $\begin{array}{l}1735 \\
1655\end{array}$ & - & 1625 & 3455 & 290 \\
\hline $\mathrm{IIb}$ & 60 & $313-315$ & $\begin{array}{l}1716 \\
1669 \\
\end{array}$ & - & 1620 & 3446 & 276 \\
\hline IIc & 45 & $148-150$ & $\begin{array}{l}1714 \\
1663\end{array}$ & - & 1618 & 3446 & 264 \\
\hline IId & 48 & $131-133$ & $\begin{array}{l}1711 \\
1667\end{array}$ & - & 1622 & 3433 & 258 \\
\hline IIe & 42 & $145-147$ & $\begin{array}{l}1716 \\
1656 \\
\end{array}$ & - & 1625 & 3441 & 276 \\
\hline
\end{tabular}

* All the compounds were of white color. 


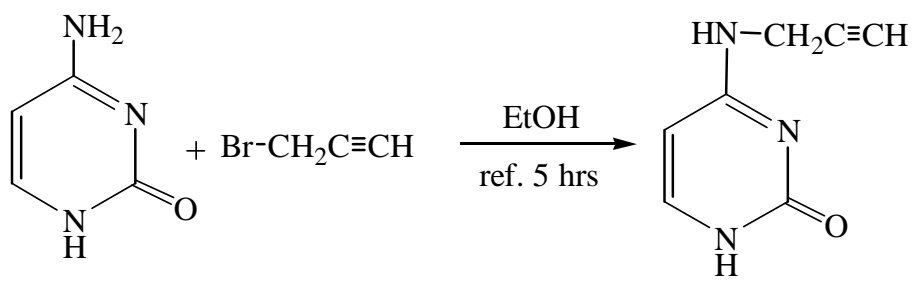

(I)

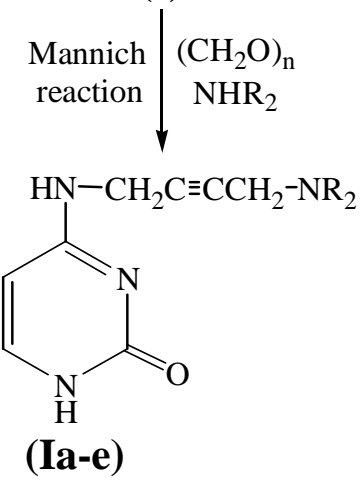

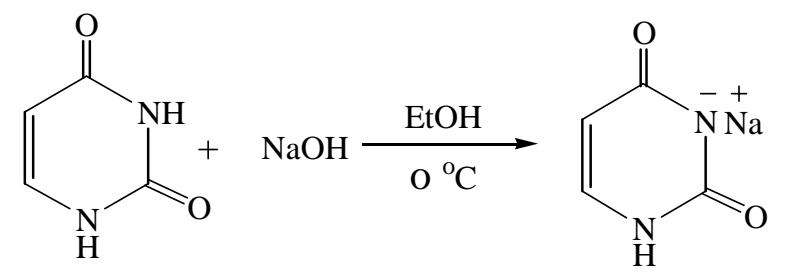<smiles>C#CCBr</smiles>
ref. $3 \mathrm{hrs}$<smiles>[R10]CC#CCn1c(=O)cc[nH]c1=O</smiles><smiles>[H][R10](C)(C)c1cc(=O)n(CC#C)c(=O)[nH]1</smiles>

(IIa-e)

(II)

\begin{tabular}{|c|c|c|}
\hline Compd. No. & Compd. No. \\
\hline Ia , IIa & Id , IId \\
\hline Ib, $\mathrm{IIb}$ & Ie , IIe \\
\hline Ic, IIc & \\
\hline
\end{tabular}

Scheme (1) 


\section{RESULTS AND DISCUSSION}

It is well known that many acetylenic amines derivatives are pharmaceutically active compounds. This fact was confirmed from the mentioned previous studies in the introduction. Accordingly, the synthesis of acetylenic amines derivatives containing cytosine and uracil moieties may show characteristic biological activity.

Therefore, two series of acetylenic amines derivatives have been synthesized using cytosine and uracil as a starting material in the Mannich synthesis as shown in scheme (1).

The synthesized acetylenic amines derivatives (Ia-e \& IIa-e) have been investigated according to their physical and spectroscopic data (IR and UV) (Parikh, 1974). Other supporting evidence is the positive Tollen test for the acetylenic hydrogen in proporgyl compounds (I ,II) which became negative test in Mannich products.

The IR. spectra of compounds (Ia-e) showed strong absorption bands at (1646-1655) $\mathrm{cm}^{-1}$ for the amidic carbonyls frequencies, another strong absorption bands for the two bands $(\mathrm{C}=\mathrm{N} \& \mathrm{C}=\mathrm{C})$ which overlapped at the region $(1614-1636) \mathrm{cm}^{-1}$. While the broad absorption bands at (3418-3446) $\mathrm{cm}^{-1}$ is due to $v \mathrm{~N}-\mathrm{H}$. The broad band at $3169 \mathrm{~cm}^{-1}$ which appeared for the acetylenic hydrogen in compound (I) is disappeared in Mannich products (Ia-e) as shown in Table (1).

The IR. Spectra of compounds (IIa-e) showed two strong absorption bands at the regions (1711-1735) $\mathrm{cm}^{-1}$ and (1656-1669) $\mathrm{cm}^{-1}$ due to the asymmetric and symmetric stretching vibrations of the imidic carbonyl groups, strong absorption bands appeared at $(1618-1625) \mathrm{cm}^{-1}$ for $v \mathrm{C}=\mathrm{C}$, a broad absorption band appeared at $(3433-3455) \mathrm{cm}^{-1}$ for the amidic hydrogen. Also the strong band at $3236 \mathrm{~cm}^{-1}$ which appeared for the acetylenic hydrogen in compound (II) is disappeared in Mannich products (IIa-e) as shown in Table (1).

The UV. spectra of compounds (Ia-e and IIa-e) showed higher $\lambda$ max. values as compounds with those of compounds (I and II). This is due to the appearance of conjugation effect which increase $\lambda$ max values and cause bathochromic shift in the $n \longrightarrow \pi^{*}$ transition of these compounds. 


\section{REFERENCES}

Al-Ajely, M.S.; Basher, H.A. ; Hussin, H.Y. (2003). Synthesis of some aminobutynyl-N[tetra(or cghorohexa) hydrophthalogl] amino acid esters. J. Edu. and Sci., 15,18.

Al-Bayati, R.I.H.; Al-Janaby, O.A. (2002). Studies on the reaction of 5,5-diethyl barbitaric acid (veronal). Nati. J. Chem., $\mathbf{5}, 113$.

Creasey, W.A.; Calabresi, P. ; Welch, A.D. (2006). Clinical and pharmacological studies with 1-p-D-arabinofuranosylcytosine (Cytosine Arabinoside). doi. Wiley.

Dahlbom, R.; Hannson, B. ; Mollberg, R. (1964). Acetylene compounds of potential pharmacological Value III. 4-dialkylamino-2-butynyl esters of benzilic acid. Chem. Abstr., 60, 9191.

da Rosa, F.A.F.; Rebelo R.A. ; Nascimentof M.G. (2003). Synthesis of new indole carboxylic acid related to the plant hormone indole acetic acid. J. Braz. Chem. Soci., 14, 11.

El-masry, A.H.; Fahmy, H.H. ; Ali Abdelwahed, S.A. ( 2000). Synthesis and Antimicrobial activity of some new benzimidazole derivatives. Molecules, 5, 1429.

Khuthier, A.H. ; Al-Abachi, F.T. (1993). Synthesis and biological activity of N(4morpholino-2-butynyl) acetate. Iraqi Patent, 2511.

Mitsumori, S.; Zhang, H.; Ha.Yeon Cheong, P.; Houk, K.N.; Tanaka, F. ; Barbas III, C.F. (2006). Direct asymmetric anti Mannich type-reactions catalyzed by a designed amino acid. J. Amer. Chem. Soci., 128, 1040.

Muhi-Eldeen, Z.M.; Ghantous, H. ; Garabet, M. (1981). Biological evaluation of N,N-bis(4-t-amino-2-butynyl) phthalamines. Iraqi, J. Sci., 22, 155.

Sheat, M. A. ; Dawood, A. A. (2004). Synthesis and study of some acetylenic amine derivatives of Isatin as antibacterial agents. Raf. J. Sci.,15, 44.

Parikh, V.M. (1974)." Absorption Spectroscopy of Organic Molecules". Addision-Wesley Publishing Company, London, 325p.

Rutledge, Th. F. (1968). "Acetylenic Compounds Preparation and Substitution Reaction." New York, Reinhold Corporation, 314p.

Wilson, A.; Sclhd, H.O. ; Model, W. (1975). "Applied Pharmacology". Churchill Livingstone, 11th edn., 133p.

Yamamoto, J. ; Toide, K. (1981). Pharmacological analysis of the combined effect of FT and uracil. www.ncbi.nlm.nih.gov/pubmed/6794578. 